\title{
Prevalence and zoonotic potential of canine hookworms in Malaysia
}

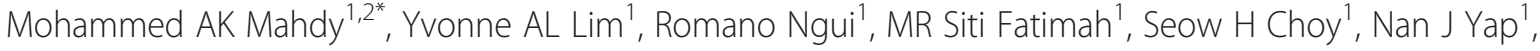
Hesham M Al-Mekhlafi ${ }^{1,2}$, Jamaiah Ibrahim ${ }^{1}$ and Johari Surin ${ }^{1}$

\begin{abstract}
Background: Canine hookworm infection is endemic in Southeast Asian countries with a prevalence ranging from $70 \%$ to $100 \%$, with zoonotic transmission representing a potentially significant public health concern. However, there are limited data available on the prevalence of canine hookworms in Malaysia. This study was conducted to determine the prevalence of hookworm and Ancylostoma species among dogs in Malaysia.

Methods: Faecal samples were collected from 221 dogs living in urban areas, rural areas and animal shelters in Selangor. Faecal samples were processed using the formal-ether concentration technique followed by wet mount preparation and iodine staining for the detection of hookworm eggs. Samples positive for hookworm eggs were examined using PCR, targeting ITS2 and 28 s rRNA region, and subsequently sequenced in both directions. The sequences were phylogenetically analysed using MrBayes for Bayesian Inference.
\end{abstract}

Results: The overall prevalence of hookworm among dogs was $48 \%(95 \% \mathrm{Cl} ; 41.41-54.95)$. Rural stray dogs had the highest prevalence $71.4 \%$ (95\%Cl; 61.13-81.49) followed by urban stray dogs, recording 48\% (95\%Cl; 34.15-61.85) and lastly dogs in shelters with $28.7 \%(95 \% \mathrm{Cl} ; 19.56-37.84)$. Logistic regression identified rural stray dogs as a high risk group $(O R=4.55,95 \% ; 2.50-8.31)$ and keeping dogs in shelters as a protective factor $(O R=0.24,95 \% ; 0.14-0.43)$. Molecular methods identified both Ancylostoma ceylanicum and Ancylostoma caninum with A. ceylanicum being predominant among urban stray dogs. Rural dogs had a higher prevalence of $A$. caninum than $A$. ceylanicum, while both species showed equal distribution among dogs in shelters. Phylogenetic analysis placed A. ceylanicum isolated from dogs in one group with A. ceylanicum human isolates.

Conclusion: This study indicates that dogs have the potential to act as reservoir hosts of human hookworm infection in Malaysia. This finding necessitates the inclusion of dogs in any interventions to combat hookworm in the country.

Keywords: Hookworm, Dogs, A. ceylanicum, A. caninum, Malaysia

\section{Background}

Canine hookworm infection is endemic in Southeast Asian countries with a prevalence ranging from $70 \%$ to $100 \%$, with zoonotic transmission representing a potentially significant public health concern [1-3]. Dog hookworms include Ancylostoma caninum, Ancylostoma braziliense, Ancylostoma ceylanicum and Uncinaria stenocephala. Of these species, only A. ceylanicum develops to adult in humans, causing patent enteric hookworm

\footnotetext{
* Correspondence: alsharaby9@yahoo.com

'Department of Parasitology, Faculty of Medicine, University of Malaya, 50603 Kuala Lumpur, Malaysia

${ }^{2}$ Department of Parasitology, Faculty of Medicine, Sana'a University, Sana'a, Yemen
}

\section{Biomed Central}

infection $[4,5]$. On the other hand, A. caninum, occasionally reaches adulthood in humans, causing eosinophilic enteritis [6-8].

Although A. braziliense is the predominant species which causes hookworm related cutaneous larva migrans (CLM), the late larval stage of $A$. caninum has been implicated in CLM [9], leading to the lesser common follicular dermatitis [10-12]. Caninum larval stage has also been suspected as a cause of diffuse unilateral subacute neuroretinitis [13] and has been found intracellularly within muscle fibers [14]. Hookworm-related CLM cases have been reported from Malaysian patients [15-19] and in tourists who have visited Malaysia [20-22]. 
Although human hookworm infections in Malaysia continue to cause significant morbidity, particularly among disadvantaged communities [23-28], there are limited data available on the prevalence of canine hookworms [29-31]. A recent study among human populations using molecular tools showed that A. ceylanicum represented $23.4 \%$ of human hookworm infections. The study not only isolated $A$. ceylanicum from humans but also from dogs living in close contact with these humans and statistical analysis identified contact with dogs and cats as a significant predictor of human hookworm infections [32]. The present study will be applying molecular tools in combination with classical parasitological methods to determine the prevalence and genetically characterize canine hookworm from different locations (i.e., urban areas, rural areas and animal shelters). This study will unfold the potential role of dogs as possible reservoir hosts of human hookworm infections.

\section{Methods}

\section{Samples and microscopy}

The study was conducted among dogs from three different locations, which included rural stray dogs in Selangor and Pahang, urban stray dogs from Kuala Lumpur and dogs from animal shelters in Selangor (Figure 1). Compared to the stray dogs in rural and urban communities, dogs in animal shelters do undergo periodic deworming.

Faecal samples were collected in wide mouth and screw capped faecal containers with attached scoops, which were properly labelled. The collected faecal samples were transported to the Department of Parasitology, Faculty of Medicine, University of Malaya for further analysis in the same day. Stool samples were processed using the formalin-ether concentration technique. Direct wet mount was prepared by mixing a small amount (approximately 1 gram) of faeces in a drop of iodine on a clean and dry slide. The smear was covered with a cover slip and examined under a light microscope starting from low power $(10 \mathrm{x})$ to high power magnification $(40 \mathrm{x})$ for the presence of hookworm-like eggs.

\section{Molecular analysis}

Genomic DNA was extracted directly from positive faecal sample using PowerSoil DNA Kit (Mo Bio, cat. no. 12888-100, CA, USA) according to manufacturer's instructions. Final elution of DNA was made in $50 \mu \mathrm{l}$ of elution buffer instead of $200 \mu \mathrm{l}$ as recommended by the manufacturer. The extracted DNA was stored at $-20^{\circ} \mathrm{C}$ until required for PCR amplification.

A partial region $(\approx 310 \mathrm{bp})$ of internal transcribed spacer ITS-2 and $28 \mathrm{~S}$ rRNA region of Ancylostoma spp. was amplified using a forward primer NC1 (5'-ACG TCT GGT TCA GGG TTC TT-3') and reverse primer NC2 (5'-TTA GTT TCT TTT CCT CCG CT-3'). Control samples without DNA (negative control/DNA blank) and with hookworm genomic DNA (positive control) were included in each PCR run. The PCR was carried out in a $50 \mu \mathrm{l}$ final PCR mixture containing $1 \mathrm{X}$ PCR buffer, $200 \mu \mathrm{M}$ dNTPs, $1 \mathrm{mM} \mathrm{MgCl}$, $10 \mathrm{pmol}$ of each primer, 5 $\mathrm{U}$ Taq polymerase and $6 \mu \mathrm{l}$ of DNA template. The cycling conditions were as follows: denaturation at $94^{\circ} \mathrm{C}$ for $5 \mathrm{~min}$, followed by 30 cycles of $94^{\circ} \mathrm{C}$ for $30 \mathrm{~s}$ (denaturing), $55^{\circ} \mathrm{C}$ for $30 \mathrm{~s}$ (annealing), $72^{\circ} \mathrm{C}$ for $30 \mathrm{~s}$ (extension) and a final extension at $72^{\circ} \mathrm{C}$ for $7 \mathrm{~min}$. PCR products were subjected for electrophoresis on 1.2\% agarose gel and stained with Cybersafe stain.

The amplicons were purified using QIAquick Gel Extraction Kit (QIAgen, cat. no. 28104, Hilden, Germany) according to the manufacturer's instructions. All the purified amplicons were sent for DNA sequencing in both directions using forward and reverse primers with an ABI 3730XL sequencer (Bioneer Corporation, South Korea). Sequence chromatograms were viewed using Sequence Scanner version 1.0 programme (Applied Biosystems, USA). Forward and reverse sequences were edited, manually aligned and the consensus sequence was created for each sample using the BioEdit Sequence Alignment Editor Programme (http://www.mbio.ncsu.edu). The similarity between each consensus sequence was then compared to previously published sequences of hookworm using the Basic Local Alignment Search Tool (BLAST) (http://blast.ncbi.nlm.nih.gov). Sequences generated in this study were deposited in GenBank, under the accession numbers (JQ673419 - JQ673426). Phylogenetic analysis was carried out by Bayesian Inference using Monte Carlo Markov Chain (MCMC) in MrBayes 3.1.2 [33]. The General Time Reversible (GTR) model of evolution was used for nucleotide substitution [34] with gamma distribution rate. Reference sequences from previous published studies were selected for phylogenetic analysis (Figure 2). The percentage of replicate trees in which the associated hookworm isolates were clustered together in the bootstrap test values (1000 replicates) is shown next to the branches.

\section{Statistical analysis}

Data were analyzed using SPSS programmed for windows version 11.5 (SPSS Inc., Chicago.IL, USA). Univariate and multivariate analysis using logistic regression were applied to identify risk factors. Chi-square was used to investigate the association between variables. The significance was defined as $p<0.05$.

\section{Results}

\section{Prevalence and distribution}

A total of 221 faecal samples were collected from dogs consisting of 94 samples from dog shelters, 77 samples from rural stray dogs [32] and 50 from urban stray dogs. 


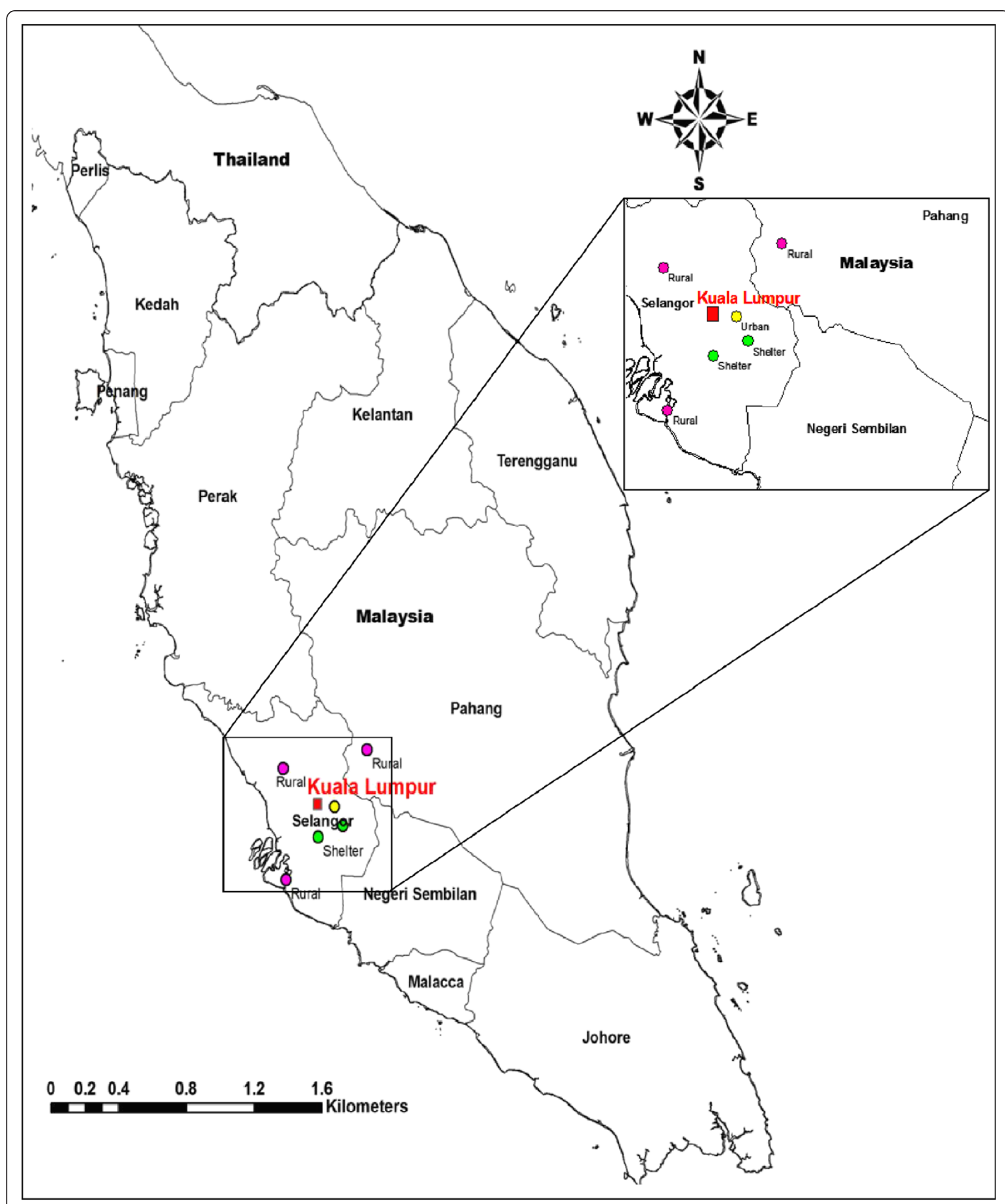

Figure 1 Map of the sampling areas.

The overall prevalence of hookworm through microscopy detection was $48 \%(95 \% \mathrm{CI} ; 41.41-54.95)$. The prevalence was the highest among rural stray dogs
(71.4\%, 95\%CI; 61.13-81.49) followed by urban stray dogs $(48 \%, 95 \% \mathrm{CI} ; 34.15-61.85)$ and finally dogs in shelters $(28.7 \%$, 95\%CI; $19.56-37.84)$ (Table 1). Multivariate 


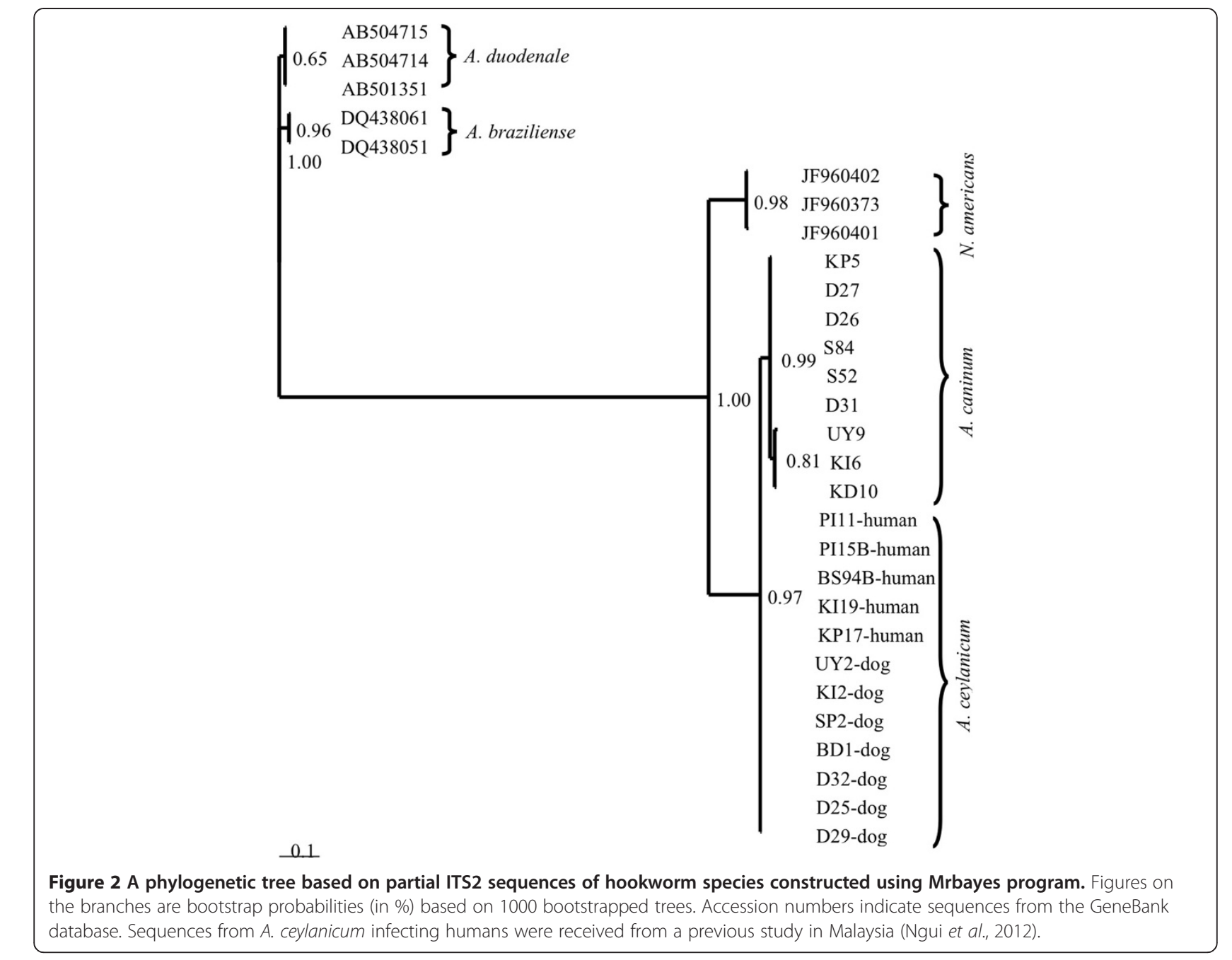

analysis showed that rural stray dogs are at a five fold higher risk of hookworm infection compared to dogs living in other locations (OR $=4.55,95 \% ; 2.50-8.31)$. Keeping dogs in shelters appeared to be a protective factor $(\mathrm{OR}=0.24,95 \%$; 0.14-0.43) (Table 2).

\section{Species identification and distribution}

Specimens positive for hookworm using microscopy (106) were subjected to PCR followed by DNA sequencing based on a partial region $(\approx 310 \mathrm{bp})$ of ITS2 and

Table 1 Prevalence of hookworm infection among dogs according to locations

\begin{tabular}{lccc}
\hline Variable & $\begin{array}{c}\text { Examined } \\
\mathbf{n}\end{array}$ & $\begin{array}{c}\text { Infected } \\
\mathbf{n ~ ( \% )}\end{array}$ & $\mathbf{9 5 \% ~ C l}$ \\
\hline Rural stray dogs & 77 & $55(71.4)$ & $61.31-81.49$ \\
\hline Urban stray dogs & 50 & $24(48)$ & $34.15-61.85$ \\
\hline Dogs in shelters & 94 & $27(28.7)$ & $19.56-37.84$ \\
\hline Total & 221 & $106(48)$ & $41.41-54.95$ \\
\hline
\end{tabular}

28 s rRNA for species identification. Of these, 82 were PCR positive and successfully sequenced. Comparison of these sequences with hookworm sequences deposited in the GenBank database using BLAST showed that 52\% (43 of 82) were A. ceylanicum and 48\% (39 of 82) were A. caninum. The study indicted that $A$. ceylanicum was predominant among urban stray dogs and equally distributed with $A$. caninum in dogs living in shelters. In rural communities, stray dogs were infected more with A. caninum than A. ceylanicum (Table 3 ).

\section{Phylogenetic analysis}

Sixteen sequences from this study representing the three groups of dogs (i.e., dogs in shelters, urban stray and rural stray dogs) together with 8 reference sequences obtained from the GenBank database and 5 sequences representing A. ceylanicum isolated from humans in Malaysia [32] were used in the phylogenetic analysis using MrBayes software for Bayesian Inference (Figure 2). A. ceylanicum sequences isolated from humans and 
Table 2 Univariate and multivariate analysis of the association of hookworm with locations $(n=221)$

\begin{tabular}{lcccc}
\hline Variable & & $\begin{array}{c}\text { Examined } \\
(\mathbf{n})\end{array}$ & $\begin{array}{c}\text { Infected } \\
\mathbf{n}(\mathbf{\%})\end{array}$ & OR (95\% Cl) \\
\hline Rural stray dogs* & Yes & 77 & $55(71.4)$ & $4.55(2.50-8.31)$ \\
\hline & No & 144 & $51(35.4)$ & 1 \\
\hline Urban stray dogs & Yes & 50 & $24(48.0)$ & $1.00(0.53-1.88)$ \\
\hline & No & 171 & $82(48.0)$ & 1 \\
\hline Dogs in shelters* & Yes & 94 & $27(28.7)$ & $0.24(0.14-0.43)$ \\
\hline & No & 127 & $79(62.2)$ & 1 \\
\hline
\end{tabular}

* Confirmed by stepwise conditional logistic regression.

dogs were grouped together with strong support (0.97). A. caninum sequences representing the three groups of dogs were placed in one cluster with 0.99 bootstrap support. Sequences representing $A$. duodenale, A. braziliense and $N$. americanus were grouped in separated clusters.

\section{Discussion}

The overall prevalence of hookworm infections among dogs based on single faecal sampling was $48 \%$ in this study with rural stray dogs having the highest infection rate, followed by urban stray dogs and finally dogs in shelters. These findings are similar to another previous study carried out among dogs in rural and urban areas in Malaysia in which the prevalence of hookworm infection was $45 \%$. However, in the previous study by Azian et al. [29], it was found that urban dogs had the highest infection rate of hookworm. This statement was further assured by the higher contamination of soil from urban areas in the same study. This is most likely due to the presence of stray dogs which scavenge rubbish and defecate all over the places [29].

In Thailand, the prevalence of hookworm infection based on microscopy was $58.9 \%$ among dogs in temple communities [2]. In China, 66.3\% of dogs in 175 farms in Heilongjiang Province had hookworm infections [35]. In rural areas in India, the prevalence of hookworm ranges from 93\% to 98\% [36,37]. The high hookworminfected stray dogs that wander and defecate in the public areas increase the risk of contamination of streets, public parks, playground and beaches with hookworm larvae. The risk of the environmental contamination was

Table 3 The distribution of Ancylostoma species among dogs based on locations

\begin{tabular}{llllll}
\hline \multicolumn{7}{c}{ Prevalence n (\%) } \\
\hline & Examined & A. ceylanicum & A. caninum & $x^{2}$ & $P$ value \\
\hline Dogs in shelters & 16 & $8(50.0)$ & $8(50.0)$ & 0.047 & $P>0.05$ \\
\hline Urban stray dogs & 21 & $16(76.2)$ & $5(23.8)$ & 6.38 & $P<0.05$ \\
\hline Rural stray dogs & 45 & $19(42.2)$ & $26(57.8)$ & 4.17 & $P<0.05$ \\
\hline Total & 82 & $43(52.4)$ & $39(47.6)$ & & \\
\hline
\end{tabular}

confirmed by the detection of hookworm larvae of animal origin in sand samples from Caribbean beaches [38]. It was also found that all travelers who visited Northeast Brazil had acquired hookworm-related CLM during their stay at the beaches [39]. Furthermore, soil contamination with hookworm larvae caused outbreaks of CLM in kindergartens [40], public parks [41], schools [42] and among children playing with sand boxes [43].

Multivariate analysis indicated that rural stray dogs are more exposed to hookworm infection and keeping them in shelters protects them from the infection. High rates among rural dogs could be attributed to contaminated soil in the rural areas with hookworm larvae of freeroaming dogs and cats. Soil contamination could also be aggravated by poor human sanitation behavior. In addition, the soil in most rural communities is muddy and moist which favours the development of hookworm larvae [44]. The present study identified that keeping dogs in shelters reduces that chance of dogs acquiring hookworm infection, as they will be less likely to be exposed to the infection compared to stray dogs and will undergo regular de-worming.

In the present study, both A. ceylanicum and A. caninum have been isolated from dogs. Phylogenetic analysis using sequences of $A$. ceylanicum isolated from dogs and reference sequences of $A$. ceylanicum isolated from humans placed all dogs and human isolates in one group with high bootstrap support (figure 2). This clustering indicates that $A$. ceylanicum may play a part in the transmission of human hookworm in Malaysia. Due to the inability to differentiate between species causing human hookworm based on egg morphology, most of the previous studies carried out in Malaysia did not identify the species [23-27]. Thus, it is likely that A. ceylanicum has been overlooked in the aetiology of human hookworm in Malaysia.

However, a recent study based on molecular methods, conducted in the rural community reported A. ceylanicum as the second species causing human hookworm infection [32]. The ability of $A$. ceylanicum to produce patent infections in humans has been reported $[2,3,5,45,46]$. In addition, molecular study conducted in Laos showed that one third of human hookworm infections are caused by $A$. ceylanicum and this species was responsible for $85 \%$ of hookworm infections among dogs [3]. The detection of A. ceylanicum in humans and dogs was also reported in a recent study conducted in Laos [47]. In a survey conducted in Thailand, A. ceylanicum was recorded as the predominant species causing hookworm in dogs and was detected in humans. In the same study, only human cases infected with $A$. ceylanicum suffered chronic abdominal disturbance [2]. These reports of $A$. ceylanicum infecting humans and dogs in the same community highlight the important role of dogs in the 
natural transmission of human hookworm in Southeast Asian countries which warrant further investigations. Therefore, the role of dogs in human hookworm transmission should be considered during the implementation of intervention measures to combat the disease, such as, mass chemotherapy which should be combined with a proper dog management programme for effective control.

In the present study, A. caninum was found in $48 \%$ of the infected dogs. This finding is concurrent with reports from Thailand [2], India [36] and Australia [48]. Ancylostoma caninum can establish pathogenic human infections dependent on the migration of L3 to the ectopic site in the human host. Of them, CLM is the most common clinical manifestation [9]. There are limited reports of CLM among local populations in Malaysia [15-19]. Yap found that of 31 patients with CLM referred to Kuala Lumpur general hospital, only $45.2 \%$ had the correct diagnosis by referred primary care physicians [15]. Missing the diagnosis of CLM for other pruritic skin manifestation might underestimate the actual incidence of CLM. Among travelers returning from Malaysia, CLM was diagnosed in 13 cases of 42 patients with dermatologic diagnosis in the period from 1997 to 2006 [20]. However, it is not clear which Ancylostoma species caused these CLM cases. Hookworm-related CLM is usually caused by $A$. braziliense, A. caninum, A. tubaeforme and Uncinaria stenocephala $[9,49]$. Since no reports of $A$. tubaeforme and $U$. stenocephala in Malaysia and only one case of $A$. braziliense was reported to date [32], we assume that $A$. caninum might be the potential species which caused the hookworm-related CLM in this country.

\section{Conclusion}

This study showed high prevalence of hookworm among dogs in Malaysia especially among stray dogs. This highlights the risk of these infected dogs contaminating public areas with hookworm larvae. The identification of $A$. ceylanicum indicates that dogs may represent reservoir hosts of human hookworm since this species has been confirmed to cause patent infection in humans which warrant further studies on human and dogs in the same location. The high prevalence of A. caninum shows that people are at risk of getting hookworm-related CLM, which should be considered in the diagnosis of pruritic skin manifestations. Dogs should be considered as a significant source of human hookworm infection in Malaysia and included in the parasite control programme to minimize the shedding of hookworm eggs. It is crucial that preventive measures such as preventing animals from defecating in the public areas and beaches, cleaning up animal waste and educating people to wear protective footwear while they are in contact with soil or sandy beaches be strictly implemented especially in public places.

\section{Competing interests}

The authors declare that they have no competing interests.

\section{Acknowledgments}

The author would like to thank the animal refugee's centres such as DBKL, SPCA and PAWS for giving us permission to collect the faecal samples from canines. The study was supported by University of Malaya Research Grant (RG022-09SUS) and University of Malaya High Impact Research Grant (J-00000-73587).

\section{Authors' contributions}

MAKM, YALL and JS designed the study; MRSF, SHC, RN and NJY did the field work and the lab work; MAKM and HMA analyzed the data; MAKM drafted the manuscript; MAKM, YALL, RN, HMA and JS revised the manuscript. All authors have read and agreed with the content of the submitted manuscript.

Received: 8 March 2012 Accepted: 7 May 2012

Published: 7 May 2012

\section{References}

1. Thompson RC, Conlan JV: Emerging issues and parasite zoonoses in the SE Asian and Australasian region. Vet Parasitol 2011, 181(1):69-73.

2. Traub RJ, Inpankaew T, Sutthikornchai C, Sukthana Y, Thompson RC: PCR-based coprodiagnostic tools reveal dogs as reservoirs of zoonotic ancylostomiasis caused by Ancylostoma ceylanicum in temple communities in Bangkok. Vet Parasitol 2008, 155(1-2):67-73.

3. Conlan JV, Sripa B, Attwood S, Newton PN: A review of parasitic zoonoses in a changing Southeast Asia. Vet Parasitol 2011, 182(1):22-40.

4. Tu CH, Liao WC, Chiang TH, Wang HP: Pet parasites infesting the human colon. Gastrointest Endosc 2008, 67(1):159-160. doi:commentary 160.

5. Anten JF, Zuidema PJ: Hookworm infection in Dutch servicemen returning from West New Guinea. Trop Geogr Med 1964, 64(756):216-224

6. Landmann JK, Prociv P: Experimental human infection with the dog hookworm, Ancylostoma caninum. Med J Aust 2003, 178(2):69-71.

7. Prociv $P$, Croese J: Human eosinophilic enteritis caused by dog hookworm Ancylostoma caninum. Lancet 1990, 335(8701):1299-1302.

8. Croese J, Loukas A, Opdebeeck J, Fairley S, Prociv P: Human enteric infection with canine hookworms. Ann Intern Med 1994, 120(5):369-374.

9. Bowman DD, Montgomery SP, Zajac AM, Eberhard ML, Kazacos KR: Hookworms of dogs and cats as agents of cutaneous larva migrans. Trends Parasitol 2010, 26(4):162-167.

10. Caumes E, Ly F, Bricaire F: Cutaneous larva migrans with folliculitis: report of seven cases and review of the literature. Br J Dermatol 2002, 146(2):314-316.

11. Malvy D, Ezzedine K, Pistone T, Receveur MC, Longy-Boursier M: Extensive cutaneous larva migrans with folliculitis mimicking multimetameric herpes zoster presentation in an adult traveler returning from Thailand. J Travel Med 2006, 13(4):244-247.

12. Rivera-Roig V, Sanchez JL, Hillyer GV: Hookworm folliculitis. Int J Dermatol 2008, 47(3):246-248.

13. Garcia CA, Sabrosa NA, Gomes AB, Segundo Pde S, Garcia Filho CA, Sabrosa AS: Diffuse unilateral subacute neuroretinitis-DUSN. Int Ophthalmol Clin 2008, 48(3):119-129.

14. Little MD, Halsey NA, Cline BL, Katz SP: Ancylostoma larva in a muscle fiber of man following cutaneous larva migrans. AmJTrop Med Hyg 1983, 32(6):1285-1288.

15. Yap FB: Cutaneous larva migrans in Hospital Kuala Lumpur, Malaysia: rate of correct diagnosis made by the referring primary care doctors. Trans R Soc Trop Med Hyg 2011, 105(7):405-408.

16. Yap FB: Creeping eruption. Int J Infect Dis 2010, 14(6):e545.

17. Hamat RA, Rahman AA, Osman M, Unyah NZ, Abdullah WO, Isa NH: Cutaneous larva migrans: a neglected disease and possible association with the use of long socks. Trans $R$ Soc Trop Med Hyg 2010, 104(2):170-172.

18. Hanjeet K, Ow Yang CK, Mak JW: Cutaneous larva migrans-report of three probable cases. Med J Malaysia 1988, 43(3):263-266. 
19. Robson NZ, Othman S: A case of cutaneous larva migrans acquired from soiled toilet floors in urban Kuala Lumpur. Med J Malaysia 2008, 63(4):331-332.

20. Lederman ER, Weld LH, Elyazar IR, von Sonnenburg F, Loutan L, Schwartz E, Keystone JS: Dermatologic conditions of the ill returned traveler: an analysis from the GeoSentinel Surveillance Network. Int J Infect Dis 2008, 12(6):593-602.

21. Bouchaud O, Houze S, Schiemann R, Durand R, Ralaimazava P, Ruggeri C, Coulaud JP: Cutaneous larva migrans in travelers: a prospective study, with assessment of therapy with ivermectin. Clin Infect Dis 2000, 31 (2):493-498.

22. Veraldi S, Rizzitelli G: Effectiveness of a new therapeutic regimen with albendazole in cutaneous larva migrans. Eur J Dermatol 1999, 9(5):352-353.

23. Al-Mekhlafi M, Atiya A, Lim Y, Mahdy A, Ariffin W, Abdullah H, Surin J: An unceasing problem: soil-transmitted helminthiases in rural Malaysian communities. Southeast Asian J Trop Med Public Health 2007, 38(6):998-1007.

24. Al-Mekhlafi MH, Surin J, Atiya AS, Ariffin WA, Mahdy AK, Abdullah HC: Anaemia and iron deficiency anaemia among aboriginal schoolchildren in rural Peninsular Malaysia: an update on a continuing problem. Trans $R$ Soc Trop Med Hyg 2008, 102(10):1046-1052.

25. Al-Mekhlafi MH, Surin J, Atiya AS, Ariffin WA, Mahdy MAK, Che Abdullah $\mathrm{H}$ : Pattern and predictors of soil-transmitted helminth reinfection among aboriginal schoolchildren in rural Peninsular Malaysia. Acta Trop 2008, 107(2):200-204

26. Ngui R, Ishak S, Chuen CS, Mahmud R, Lim YA: Prevalence and risk factors of intestinal parasitism in rural and remote West Malaysia. PLoS Negl Trop Dis 2011, 5(3):e974.

27. Lim YA, Romano N, Colin N, Chow SC, Smith HV: Intestinal parasitic infections amongst Orang Asli (indigenous) in Malaysia: has socioeconomic development alleviated the problem? Trop Biomed 2009, 26(2):110-122.

28. Ahmed A, Al-Mekhlafi HM, Choy SH, Ithoi I, Al-Adhroey AH, Abdulsalam AM, Surin J: The burden of moderate-to-heavy soil-transmitted helminth infections among rural malaysian aborigines: an urgent need for an integrated control programme. Parasit Vectors 2011, 4:242

29. Azian MY, Sakhone L, Hakim SL, Yusri MY, Nurulsyamzawaty Y, Zuhaizam $\mathrm{AH}$, Rodi IM, Maslawaty MN: Detection of helminth infections in dogs and soil contamination in rural and urban areas. Southeast Asian J Trop Med Public Health 2008, 39(2):205-212.

30. Choo J, Pang E, Prociv P: Hookworms in dogs of Kuching, Sarawak (north Borneo). Trans R Soc Trop Med Hyg 2000, 94(1):21-22.

31. Ramachandran CP, Balasingam E, Lim BL: Helminthic infections among domestic dogs in and around Kuala Lumpur-a preliminary report. Med J Malaya 1968, 22(3):241.

32. Ngui R, Lim YA, Traub R, Mahmud R, Mistam MS: Epidemiological and Genetic Data Supporting the Transmission of Ancylostoma ceylanicum among Human and Domestic Animals. PLoS Negl Trop Dis 2012, 6(2):e1522.

33. Huelsenbeck JP, Ronquist F: MRBAYES: Bayesian inference of phylogenetic trees. Bioinformatics 2001, 17(8):754-755.

34. Lanave C, Preparata G, Saccone C, Serio G: A new method for calculating evolutionary substitution rates. J Mol Evol 1984, 20(1):86-93.

35. Wang CR, Qiu JH, Zhao JP, Xu LM, Yu WC, Zhu XQ: Prevalence of helminthes in adult dogs in Heilongjiang Province, the People's Republic of China. Parasitol Res 2006, 99(5):627-630.

36. Traub RJ, Robertson ID, Irwin P, Mencke N, Thompson RC: The role of dogs in transmission of gastrointestinal parasites in a remote tea-growing community in northeastern India. AmJTrop Med Hyg 2002, 67(5):539-545.

37. Traub RJ, Robertson ID, Irwin P, Mencke N, Thompson RC: Application of a species-specific PCR-RFLP to identify Ancylostoma eggs directly from canine faeces. Vet Parasitol 2004, 123(3-4):245-255.

38. Esterre $P$, Agis F: Beach sand nematodes in Guadeloupe: associated public health problems. Bull Soc Pathol Exot Filiales 1985, 78(1):71-78

39. Heukelbach J, Gomide M, Araujo F Jr, Pinto NS, Santana RD, Brito JR, Feldmeier $\mathrm{H}$ : Cutaneous larva migrans and tungiasis in international travelers exiting Brazil: an airport survey. J Travel Med 2007, 14(6):374-380.

40. Lima Wdos S, de Camargo MC, Guimaraes MP: [Outbreak of cutaneous larva migrans in a nursery school in Belo Horizonte, Minas Gerais (Brazil)]. Rev Inst Med Trop Sao Paulo 1984, 26(2):122-124.

41. Santarem VA, Giuffrida R, Zanin GA: Cutaneous larva migrans: reports of pediatric cases and contamination by Ancylostoma spp larvae in public parks in Taciba, Sao Paulo State. Rev Soc Bras Med Trop 2004, 37(2):179-181.

42. Araujo FR, Araujo CP, Werneck MR, Gorski A: Cutaneous larva migrans in children in a school of center-western Brazil. Rev Saude Publica 2000, 34(1):84-85

43. Nunes CM, Pena FC, Negrelli GB, Anjo CG, Nakano MM, Stobbe NS: Presence of larva migrans in sand boxes of public elementary schools, Aracatuba, Brazil. Rev Saude Publica 2000, 34(6):656-658.

44. Loh AG, Israf DA: Tests on the centrifugal flotation technique and its use in estimating the prevalence of Toxocara in soil samples from urban and suburban areas of Malaysia. J Helminthol 1998, 72(1):39-42.

45. Wijers DJ, Smit AM: Early symptoms after experimental infection of man with Ancylostoma braziliense var. ceylanicum. Trop Geogr Med 1966, 18(1):48-52

46. Carroll SM, Grove DI: Response of dogs to challenge with Ancylostoma ceylanicum during the tenure of a primary hookworm infection. Trans $R$ Soc Trop Med Hyg 1986, 80(3):406-411.

47. Conlan JV, Khamlome B, Vongxay K, Elliot A, Pallant L, Sripa B, Blacksell SD Fenwick A, Thompson RCA: Soil-Transmitted Helminthiasis in Laos: A Community-Wide Cross-Sectional Study of Humans and Dogs in a Mass Drug Administration Environment. Am J Trop Med Hyg 2012, 86:624-634.

48. Palmer CS, Traub RJ, Robertson ID, Hobbs RP, Elliot A, While L, Rees R, Thompson RC: The veterinary and public health significance of hookworm in dogs and cats in Australia and the status of A. ceylanicum. Vet Parasitol 2007, 145(3-4):304-313.

49. Feldmeier $H$, Schuster A: Mini review: hookworm-related cutaneous larva migrans. Eur J Clin Microbiol Infect Dis 2012, 31:915-918.

doi:10.1186/1756-3305-5-88

Cite this article as: Mahdy et al:: Prevalence and zoonotic potential of canine hookworms in Malaysia. Parasites \& Vectors 2012 5:88.

\section{Submit your next manuscript to BioMed Central and take full advantage of:}

- Convenient online submission

- Thorough peer review

- No space constraints or color figure charges

- Immediate publication on acceptance

- Inclusion in PubMed, CAS, Scopus and Google Scholar

- Research which is freely available for redistribution
C) BioMed Central 